\title{
BASELINE EYEBALL BIOMETRICS ON COMPUTED TOMOGRAPHY IN MAKURDI, NORTH CENTRAL NIGERIA
}

\author{
Annongu IT ${ }^{1^{*}}$, Mohammad $\mathrm{H}^{1}$, Chia $\mathrm{M}^{1}$, Chaha $\mathrm{K}^{2}$, Magaji OG. ${ }^{3}$ \\ Department of Radiology, Benue State University Teaching Hospital, Makurdi. ${ }^{1}$ and Dalhatu Araf Specialist Hospital, Lafia, \\ Nassarawa State. ${ }^{3}$ \\ Department of Ophthalmology, Benue State University Teaching Hospital Makurdi. ${ }^{2}$
}

*Corresponding Author: Annongu, Isaac Terkimbi. Department of Radiology, College of Health Sciences/Benue State University Teaching Hospital Makurdi. E-mail: iannongu@gmail.com.

Received date: March $05^{\text {th }}$, 2018, Accepted date: March 25 $5^{\text {th }}$, 2018. Published date: April $20^{\text {th }}, 2018$

\begin{abstract}
Variations in ocular sizes exist in the population and this may be congenital or pathological. Reference values are therefore essential in management of ophthalmic pathologies in the fields of Ophthalmology and Neurology. The aim of the study was to establish computer tomography (CT) scan reference values of ocular sizes in Makurdi, north central Nigeria. To avoid unjustifiable radiation dose, data obtained for this study was on 111 patients referred on account of other medical conditions, to the Radiology department for CT brain scan using Philip Brilliance 16. Measurements were taken at mid-ocular axial slices with maximum anterior-posterior and transverse dimensions. The mean $\pm 2 \mathrm{SD}$ ) ocular sizes in anterior-posterior(AP) and transverse diameter(TD) for both eyes were $22.1 \mathrm{~mm} \pm$ $1.88 \mathrm{~mm}$ and $22.9 \mathrm{~mm} \pm 1.20 \mathrm{~mm}$ respectively. The right eye was $21.9 \mathrm{~mm} \pm 2.33 \mathrm{~mm}$ and $22.9 \mathrm{~mm} \pm 1.09 \mathrm{~mm}$ and the left eye was $22.3 \mathrm{~mm} \pm 1.24 \mathrm{~mm}$ and $23.0 \pm 1.30 \mathrm{~mm}$ in both AP and TD respectively. The measurements were slightly higher on the left. The mean ocular measurements were higher in males and were statistically significant in the transverse measurements on both sides $(\mathrm{P}<0.04)$. Adult eye size was attained at age group 11-20 years and subsequently at age $>70$ years, there was slight reduction in ocular dimensions. Established ocular sizes on CT therefore showed that males had slightly larger eyeballs in comparison to females and there was some reduction of ocular sizes with age.
\end{abstract}

Keywords; Ocular sizes, age, computed tomography, Makurdi.

\section{Introduction}

The human eye has well established spaces. Congenital and acquired variations in the depth of these spaces determine the sizes of the eyeball which may affect management of cases in the fields of Ophthalmology and Ophthalmoneurology. In ophthalmology; congenital glaucoma, eyeball trauma, cancer, retinoblastoma, macrophthalmia, microphthalmia, hypermetropia, myopia, astigmatism and presbyopia are all associated with changes in the size of the eyeball ${ }^{2,3}$
In Neurology, current interest in optic nerve sheath diameter (ONSD) and its possible connection with the intracranial pressure monitoring requires precise transverse size ocular measurements. The knowledge of normative size of the eyeball is as important as measurement of the normative ONSD. ${ }^{4}$ Ocular normogram will aid in diagnosis of raised intraocular pressure. $^{5}$

Newer Computed Tomography (CT) scans have greatly enhanced oculometric research and made it 
possible to measure ocular dimensions. With these measurements, ocular size and volume can be more accurately estimated to understand its relationship with age and sex. ${ }^{6}$ Normal values of ocular biometric studies acquired through CT-scan are affected by ethical issues related to radiation dose. Such studies on CT scans were performed for other reasons. ${ }^{7}$

The study therefore aims to establish ocular sizes in the north central Nigeria and relate it to sex and age using CT. This may provide reference values in the practice of Ophthalmology and Neurology, which may aid explanation of the relationship between ocular size and ophthalmic diseases like variation in refractive index and also add to the body of knowledge.

\section{Materials and methods}

Images of cranial CT scan and backup compact discs from the CT archives of Radiology Department of the Benue State University Teaching Hospital (BSUTH) Makurdi performed primarily for other reasons covering a 4 year period (2013 to 2016) were retrospectively examined. Images with ophthalmic pathologies or lesions such as tumours, fractures or bony lesions involving the facial bones and orbital walls were excluded from the study. Equally excluded were CT images that were not clear due to motion blurring or images that showed deformity or irregularity of the eyeball contour.

The CT scans were performed in axial planes at a thickness of $5 \mathrm{~mm}$ and a window level of 50 Hounsfield units using Philips 16 Brilliance. The slices chosen for ocular measurements were midocular slices showing the maximum axial size of the eyeball, the lens and optic nerve. The ocular dimensions were obtained in anterior-posterior (AP) diameter or axial length and transverse diameter (TD) or width of the eyeball. The AP diameter is the distance through the visual axis from the anterior corneal surface to the posterior wall of the choroid in axial view and it included the anterior chamber length, lens thickness and the vitreous chamber length. The TD is the maximum transverse diameter between the temporal and nasal ends of the eye in axial view (Fig 1).

Demographic data including the age, sex, medical history and the corresponding images were obtained from the records of the patients.

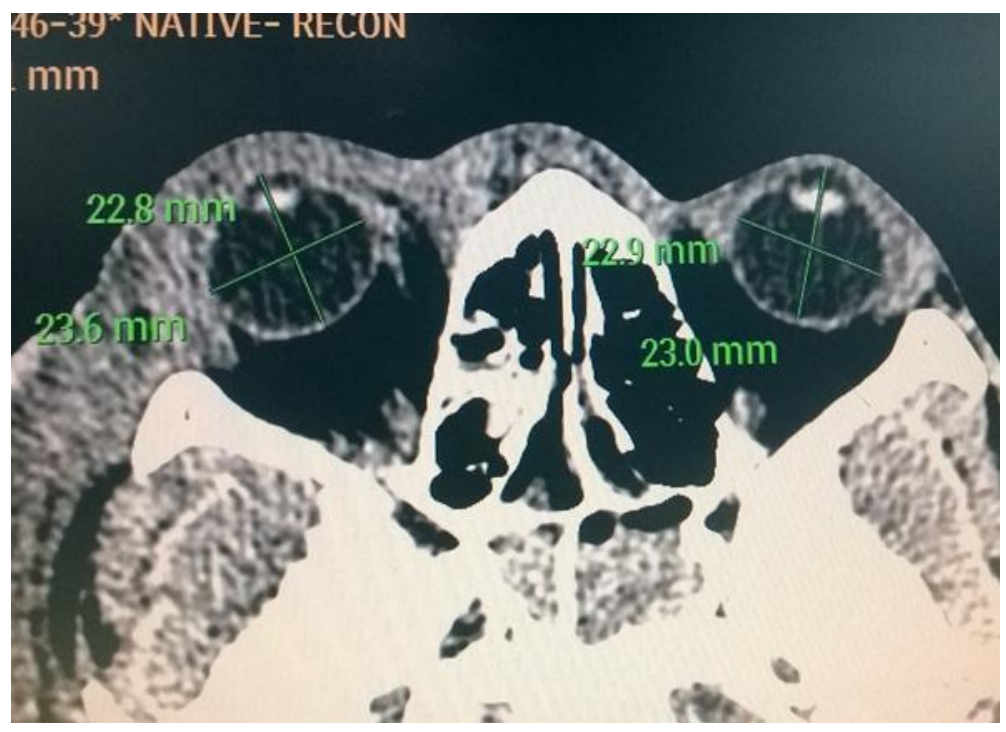

Fig 1. Axial CT scan demonstrating measurement of length and width of the eye. 


\section{Results}

A total of one hundred and eleven images were analyzed which comprised of $79(71.2 \%)$ males and $32(28.8 \%)$ females (fig 2).

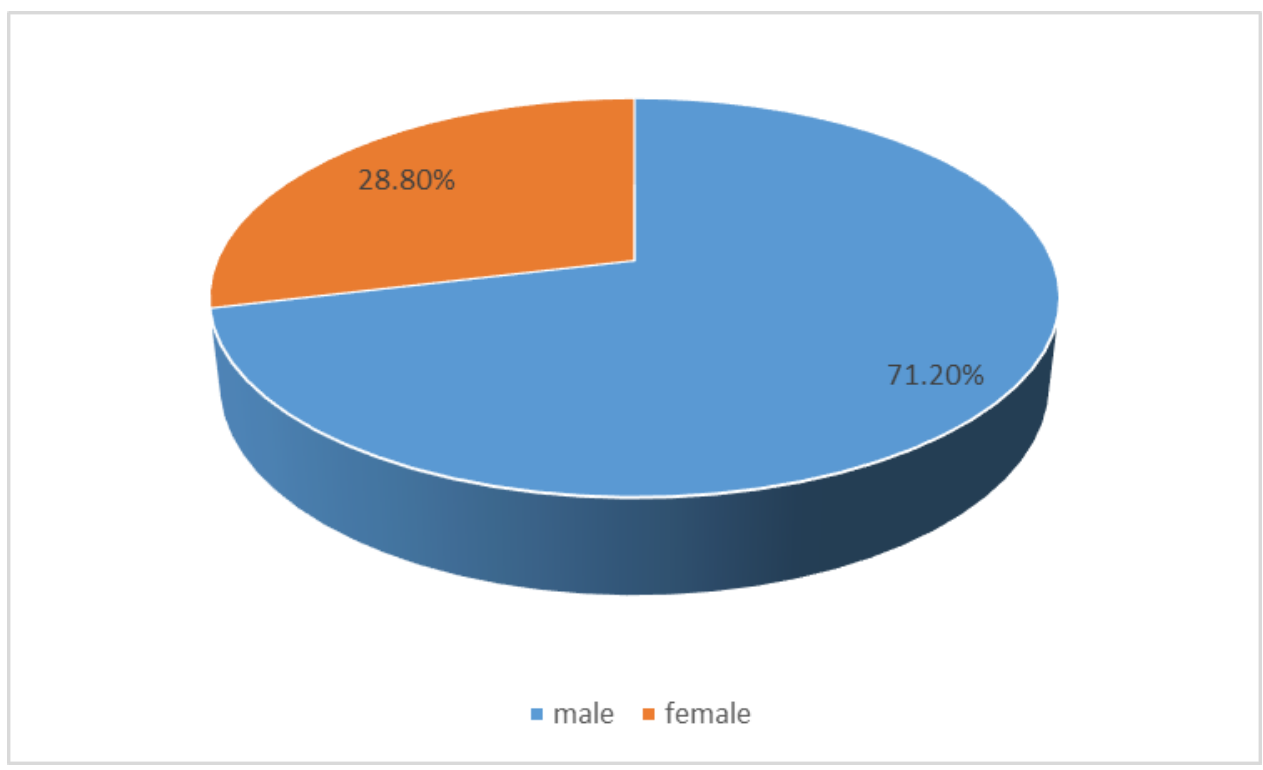

Fig 2. Pie chart showing sex distribution

The mean age studied was $40 \pm 1.79$ years. The youngest in this was 3 years and the oldest was 76 years (Figure 3 )

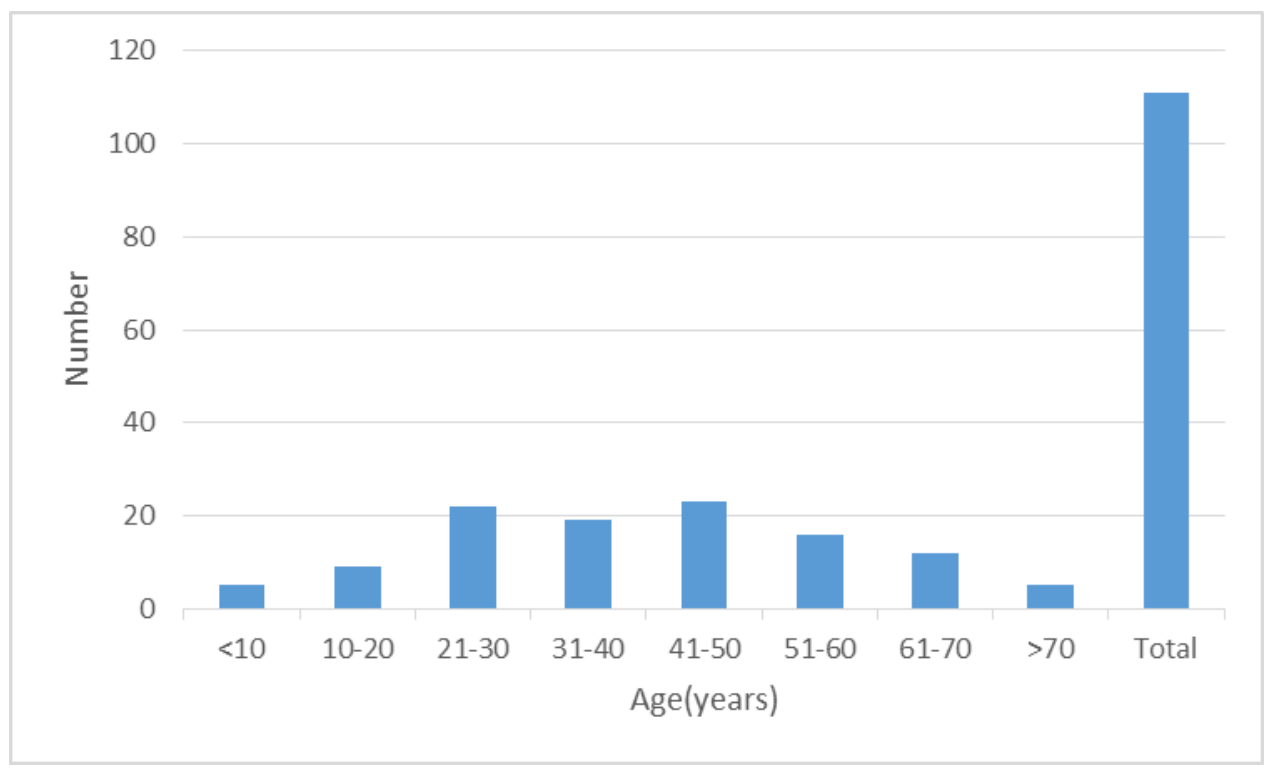

Fig 3. Bar chart showing age distribution in the study 
The mean AP and TD ocular dimensions of the right eye were $21.9 \pm 2.33$ and $22.9 \pm 1.09$ respectively; the left were $22.3 \pm 1.24$ and $23.0 \pm 1.30$ respectively while for both eyes were $22.1 \pm 1.88$ and $22.9 \pm 1.20$ respectively. (Table 1)

Table 1. Ocular dimensions in the right, left and both eyes.

$\begin{array}{llll}\text { Side } & \text { Mean }(\mathrm{mm}) & \text { Median }(\mathrm{mm}) & \text { SD } \\ \text { AP Right } & 21.9 & 22.3 & 2.33 \\ \text { TD Right } & 22.9 & 22.8 & 1.09 \\ \text { AP Left } & 22.3 & 22.3 & 1.24 \\ \text { TD Left } & 23.0 & 23.1 & 1.30 \\ \text { AP Both } & 22.1 & 22.3 & 1.88 \\ \text { TD Both } & 22.9 & 22.9 & 1.20 \\ \end{array}$

The right eyeball was slightly smaller than the left in all diameters but these differences were statistically insignificant $(\mathrm{P}>0.05)$.

There was slightly higher mean ocular dimensions in males than females and was statistically significant in the transverse measurement in both sides $[(\mathrm{P}<0.05)($ Table 2$)]$.

Table 2. Ocular dimensions in both sexes

\begin{tabular}{llll}
\hline Side & Male $(\mathrm{mm})$ & Female $(\mathrm{mm})$ & p-value \\
AP Right & $21.9 \pm 2.7$ & $21.9 \pm 1.1$ & 0.98 \\
TD Right & $23.0 \pm 1.1$ & $22.6 \pm 1.0$ & 0.04 \\
AP Left & $22.4 \pm 1.1$ & $22.1 \pm 1.6$ & 0.26 \\
TD Left & $23.7 \pm 1.3$ & $22.6 \pm 1.3$ & 0.04
\end{tabular}

Key: AP-antero-posterior.TD-transverse diameter

Ocular measurements were lowest in patients who were $\leq 10$ years and $>70$ years. From 60years, there was slight drop in the ocular dimensions however there was no statistically significant correlation between changes in ocular dimensions with age in both AP and transverse measurements [p-value of 0.83 and 0.06 for both AP and transverse measurement respectively (Table 3)].

The higher mean ocular dimensions (both AP and TD) of the left eye was maintained even on reduction of ocular dimensions with age of in both eyes, this too however was not statistically significant $[(>0.05)$ (Table 3)].

Table 3 Ocular dimensions with age distribution

\begin{tabular}{|c|c|c|c|c|}
\hline Age & $\mathrm{APR}(\mathrm{mm})$ & APL(mm) & TDR(mm) & TDL $(\mathrm{mm})$ \\
\hline$\leq 10$ & $21.2 \pm 1.1$ & $21.4 \pm 1.3$ & $21.3 \pm 1.2$ & $21.5 \pm 1.1$ \\
\hline $11-20$ & $22.6 \pm 0.5$ & $22.8 \pm 0.3$ & $23.5 \pm 0.8$ & $23.9 \pm 0.6$ \\
\hline $21-30$ & $21.7 \pm 2.2$ & $22.4 \pm 1.7$ & $22.6 \pm 0.8$ & $22.6 \pm 1.1$ \\
\hline $31-40$ & $22.4 \pm 1.2$ & $22.5 \pm 1.0$ & $23.1 \pm 1.1$ & $23.4 \pm 1.3$ \\
\hline $41-50$ & $21.5 \pm 4.4$ & $22.4 \pm 1.1$ & $23.1 \pm 1.0$ & $22.1 \pm 1.3$ \\
\hline $51-60$ & $22.0 \pm 1.1$ & $22.3 \pm 1.3$ & $23.3 \pm 1.2$ & $23.1 \pm 1.3$ \\
\hline $61-70$ & $22.4 \pm 1.2$ & $22.4 \pm 1.2$ & $22.8 \pm 1.1$ & $23.5 \pm 1.5$ \\
\hline$>70$ & $21.5 \pm 1.4$ & $21.6 \pm 1.1$ & $22.5 \pm 1.3$ & $23.1 \pm 1.4$ \\
\hline $\mathrm{p}$-value & 0.83 & 0.58 & 0.06 & 0.09 \\
\hline
\end{tabular}

Key: AP-antero-posterior.TD-transverse diameter. 


\section{Discussion}

Since 1912, the generally accepted average measurements of the eyeball diameters were $24.2 \mathrm{~mm}$, $23.7 \mathrm{~mm}$, and $23.6 \mathrm{~mm}$ for AP, TD and the vertical diameters respectively. ${ }^{8}$ Our data showed smaller sizes of the eyeball that was not up to $24.5 \mathrm{~mm}$ either in axial or in TD, however the measurements were within the accepted range of $21 \mathrm{~mm}-27 \mathrm{~mm}^{4}$ This could probably be due to the CT slide thickness of $5 \mathrm{~mm}$ used in our study as against $2-3 \mathrm{~mm}$ used by most published work.

In our study, the TD was longer than the AP diameter. This collaborates with the work of Ogbeide OU et ${ }^{5}$ and Bekerman in the study on Variations in Eyeball Diameters of the Healthy Adults. ${ }^{4}$ Saalam et $\mathrm{al}^{5}$ however showed that the AP dimensions in a study on ocular biometrics were higher than the TD lengths and also the right eyeball was slightly smaller than the left one, no concrete reasons could be adduced for these differences.

Hahn et al in a study on ocular volume measured by CT scans documented that rapid growth of the eyeball was noted during the first 24 months of age, reaching its peak between the ages of 18 and 30 years of age, after which there was a reduction. ${ }^{9}$ Similar observations was made in this study. The peak of ocular measurements was reached at age range of 1120 years in both height and width,; thereafter there was reduction in size, though not uniformly, until at age >70years which showed lower values of ocular sizes in both AP and Transverse dimensions.

It was observed in our study that the ocular dimensions were slightly higher in males and were statistically significant in the transverse measurements. Similar findings were obtained by Salaam et al and Ogbeide et al. ${ }^{10}$ possible explanation to this was attributed to the human sexual dimorphism in which the male body habitus is usually bigger than that of the female. ${ }^{5}$

\section{Conclusion}

The orbital globe ranges from $21-27 \mathrm{~mm}$ in both AP and transverse dimensions. Males have slightly higher ocular dimensions. Measurements are noted to be higher on the left eye. Adult eye size is attained at about 18-30 years and the ocular dimensions gradually declines with age.

\section{References}

1. The human eye, http://www.visiondirect.co.uk/the-humaneye[accessed $2^{\text {nd }}$ February2018].

2. Liebovitch L.S, "Why the eye is round?" in The Biology of the Eye, J. Fischbarg, Ed., pp. 5-6, Elsevier, Boston, Mass, USA, 2006

3. Igbinedion $\mathrm{B} \mathrm{O}$, Ogbeide $\mathrm{O} \mathrm{U}$. Measurement of normal ocular volume by the use of computed tomography. Niger J ClinPract 2013;16:315-9

4. Inessa B, Paul G, Michael V. Variations in Eyeball Diameters of the Healthy Adults. Journal of Ophthalmology, vol. 2014, Article ID 503645, 5 pages, 2014. doi:10.1155/2014/503645.

5. Ogbeide OU, Igbinedion BO. Ocular biometry using computed tomography: A study in Benin, Nigeria. Nig. Postg. Med J. 2014; 21(3):250-254.

6. Hahn FJ, Chu WK. Ocular volume measured by CT scans. Neuroradiology. 1984; 26(6): 419-20.

7. Salaam AJ, Aboje OA, Danjem SM, Tawe G, Salaam AA. Ocular Biometry Using Computed Tomography: In Jos, North Central Nigeria. $O R$ 2016; 5(2): 1-6.

8. Salzmann M. The Anatomy and Histology of the Human Eyeball in the Normal State, Its Development and Senescence. The University of Chicago Press, Chicago, Ill, USA, 1912.

9. Hahn FJ, Chu WK. Ocular volume measured by CT scans. Neuroradiology. 1984; 26(6):419-20.

10. Ogbeide OU, Omoti AE. Ocular volume determination in Nigerians. Pak. J. Med. Sci. 2008; 24(4):808-812. 